Las estrategias empresariales en la ciudad de Olavarría (1940-1970)

Griselda Lemiez

Question, Vol. 1, N. 62, e157, abril-junio 2019

ISSN 1669-6581 | https://doi.org/10.24215/16696581e157

http://perio.unlp.edu.ar/ojs/index.php/question

FPyCS | Universidad Nacional de La Plata

La Plata | Buenos Aires | Argentina

\title{
Las estrategias empresariales en la ciudad de Olavarría (1940-1970)
}

The business strategies in the city of Olavarría (1940-1970)

\author{
Griselda Lemiez griseldalemiez@hotmail.com \\ https://orcid.org/0000-0002-2384-878X \\ Instituto de Investigaciones Arqueológicas y Paleontológicas del \\ Cuaternario Pampeano; Facultad de Ciencias Sociales; Universidad Nacional \\ del Centro de la Provincia de Buenos Aires (Argentina)
}

\section{Resumen}

El siguiente artículo tiene por objetivo analizar las estrategias empresariales desplegadas por los empresarios del cemento durante un período determinado en una ciudad argentina. La formación de esas relaciones de poder vinculadas al desarrollo económico de la ciudad, fue acompañada de la construcción de la identidad asociada a la producción de cemento. La ciudad del cemento, 
tal como se la conoce actualmente, nace y se desarrolla como parte de una actividad industrial que fue configurando y expresando las diferentes relaciones de poder, otorgándole una identidad particular a la propia ciudad.

Palabras clave: Empresarios; poder; ciudad; identidad.

\section{Abstract}

The following article aims to analyze the business strategies deployed by cement entrepreneurs/bussinesmen during a specific period in an Argentine city. The birth of those power relations linked to the economic development of the city was accompanied by the construction of the identity associated with the cement production. The city of cement, as it is currently known these days, was born and developed as part of an industrial activity that was shaping and expressing the different power relationships, giving a particular identity to the city itself.

Keywords: Bussinesmen; power; city; identity; cement industry.

El paisaje de Olavarría está enmarcado por distintos establecimientos fabriles, cercanos espacialmente. A partir de la localidad de Loma Negra (Villa Alfredo Fortabat) y hacia el noreste, se observan la fábrica Cementos Avellaneda, luego la planta de Cemento San Martín y entre ellas numerosas caleras y canteras pequeñas de dolomita, arcilla, piedra caliza y granito. La explotación minera en la región serrana significó un foco de atracción de mano de obra y un consecuente crecimiento de la población. A las pequeñas explotaciones mineras le siguieron, en la década de 1920, las grandes industrias extractivas y productoras de cemento y cal, que crearon en su entorno núcleos habitacionales para sus trabajadores, las llamadas villas obreras. La antigua forma de producción, envasado y comercialización del cemento, requería gran cantidad de mano de obra, que además debía residir cerca de la fábrica debido a las características del ciclo continuo de producción del cemento. Asimismo, las fábricas debían situarse cerca de los yacimientos de mineral y de las canteras, como consecuencia del escaso desarrollo del transporte y la infraestructura de caminos (Villafañe, 1999). En esos espacios rurales no había un mercado de trabajo constituido ni las poblaciones cercanas ofrecían un número importante de trabajadores, por lo tanto, la necesidad de atraer y fijar a éstos en proximidades de las plantas se convirtió en una tarea prioritaria para las empresas.

Las denominadas "villas obreras" o "villas serranas", levantadas casi a la sombra de cada fábrica, 
fueron producto de la necesidad de contar con un mercado de trabajo estable. $Y$ en ellas se desarrollaron las políticas patronales destinadas a la fijación y adaptación de la mano de obras, también llamadas "obras sociales", en las cuales el otorgamiento de viviendas para las familias obreras tuvo un papel fundamental (Sierra Álvarez, 1990). Se conformó en estas empresas cementeras un sistema de fábrica con villa obrera, que funcionó durante el período 1940-1970, donde la esfera de producción y reproducción de la mano de obra se encontraban estrechamente ligadas y se regían por relaciones laborales, pero también sociales, de tipo paternalistas (Neiburg, 1988: 58).

El resultado de las estrategias empresariales no puede evaluarse sin considerar también la actitud de sus destinatarios, los trabajadores y sus familias, quienes tuvieron un papel activo desde su aplicación hasta su consolidación. Es decir que aquí consideramos a las relaciones sociales paternalistas, como una interacción compleja y dinámica entre trabajo y capital, en la cual están presentes el consentimiento obrero a las directivas patronales, así como la negociación y el intento de maximizar los beneficios del otorgamiento de esas "obras sociales". Las estrategias empresariales que desplegaron los empresarios del cemento, como parte de estos modelos empresariales y en paralelo al desarrollo económico de la ciudad, fueron acompañadas de la construcción de una identidad asociada a la producción de cemento. La ciudad del cemento, tal como se la conoce actualmente, nace y se desarrolla como parte de una actividad industrial que fue configurando y expresando las diferentes relaciones de poder, al mismo tiempo que fue construyendo una identidad particular para la propia ciudad.

\section{Estrategias empresariales, dominación y legitimidad}

La efectividad, productividad y rentabilidad de las empresas son el resultado integrado de una serie de factores económicos y tecnológicos, pero también organizativos y políticos. Para alcanzar y sostener el crecimiento de la productividad, no sólo tiene que darse un proceso de capitalización/mecanización, sino que también fue históricamente necesario que los trabajadores interiorizaran primero forzada- y luego voluntariamente la disciplina y el control, necesarios para asegurar la continuidad del proceso productivo (Gaudemar, 1981: 100). En el proceso de trabajo, la disciplina aparece como la forma normalizante de la relación de subordinación del trabajo al capital. Así, se convierte en la condición necesaria para que comience a funcionar el trabajo colectivo, donde el trabajo no es un factor más de producción, ya que se compone de sujetos históricos concretos a los que es necesario, adaptar y ajustar a las necesidades objetivas del proceso de trabajo. 
Tal como afirma Foucault, la modalidad, es decir, el modo de ser o de manifestarse que tiene la disciplina, implica una coerción ininterrumpida constantemente, que vela sobre los procesos de la actividad más que sobre su resultado y se ejerce según una condición que reticula con la mayor aproximación el tiempo, el espacio y los movimientos. A estos métodos que permiten el control minucioso de las operaciones del cuerpo, que garantizan la sujeción constante de sus fuerzas y les imponen una relación de docilidad, utilidad, es a lo que se puede llamar "disciplinas" (Foucault, 2002: 141).

En busca de un orden, las empresas han tratado de responder a su entorno competitivo desarrollando formas de disciplina y sanción que cambiaron históricamente y que se convirtieron en partes esenciales de sus estrategias. Las empresas, entendidas como sujetos históricos, van adaptando sus formas de organización en función de sus intereses productivos, que varían de acuerdo las necesidades del momento. Muy a menudo las empresas parecen dirigidas por sujetos empeñados tan solo en procedimientos contractuales y portadores de las contradicciones de la maximización de producción y beneficios (Sapeli, 1993: 110). Sin embargo, la complejidad y heterogeneidad de la dirigencia empresarial indica que no es simplemente esa necesidad lo que lleva a decisiones que terminan construyendo modelos de relaciones sociales; para entender ese comportamiento es preciso tener en cuenta que la historia de la empresa es una trama de trayectorias evolutivas y de desequilibrios dinámicos y estratégicos.

En relación a la cuestión de la disciplina industrial, durante la primera fase de expansión capitalista, los empresarios no disponían de experiencia en el control del colectivo laboral ni los trabajadores habían interiorizado las formas de comportamiento dictadas por el ritmo de la producción. La disciplina se imponía con métodos puramente coercitivos basados en los modelos disciplinarios imperantes, por ejemplo, en el ejército. Su implantación no siempre llevó al aumento de la productividad, pero sí servirá para imponer un orden estricto y cambiar el comportamiento de los trabajadores dentro de la fábrica. Las necesidades de la producción obligaron a iniciar la aplicación de otras estrategias disciplinarias, que no se basaran exclusivamente en la coerción. Con el fin de corregir el comportamiento rebelde de los trabajadores, las empresas empezaron a regular también los espacios sociales en los que los estos reproducían su fuerza de trabajo, como la vivienda, los lugares de esparcimiento y así nació la llamada "fábrica-ciudad". Allí, el empresario desarrollaba una relación paternalista con sus trabajadores, con el fin de regular la vida privada de estos, mediante diversos mecanismos disciplinarios indirectos, externos a la planta industrial (Sierra Álvarez, 1990: 10).

La acumulación de capital hubiera sido imposible sin la demarcación de horarios, reglamentos y disciplina, donde se confeccionaron y aplicaron técnicas de poder destinadas a forjar obreros 
pasivos. Esas redes de controles se constituyeron en el símbolo de la seguridad y el orden, pero también representaron una relación de reciprocidad. Y es esa dominación simbólica, en este caso representada por medio de la relación laboral paternalista, la que permitió el funcionamiento del sistema industrial capitalista. Es entonces dentro de ese sistema donde la disciplina parece actuar por cuenta propia, aparece como una forma normalizante de la relación de subordinación del trabajo al capital, que en general es aceptada como la condición necesaria para que comience a funcionar el trabajo colectivo. Allí los ejecutores de la disciplina la utilizaron como instrumento de dominación, para perpetuar su poder y su reproducción (Gaudemar, 1985: 85). La disciplina se instauró de hecho, cuando el patrón o maestro intentaba imponer a sus discípulos unos conocimientos cuyas reglas de constitución solo él podía elaborar. No es extraño que la misma se manifieste sobre todo en la fábrica, porque en ella el control del maestro-capataz se operaba sobre el proceso mismo de trabajo, sobre la forma en que el trabajador tenía que realizar su propio trabajo, a diferencia de otras formas de organización productiva. Ese control en la fábrica se encontraba legitimado por la mirada del patrón, y la disciplina tendía a aparecer fundada en las necesidades objetivas del desarrollo del proceso de trabajo.

Llegó el momento en que la disciplina que se manifestaba como vigilancia del trabajo resultó insuficiente desde el punto de vista de la producción, cuando la necesidad de mano de obra era evidente y la resistencia obrera seguía siendo posible. Es así como se impuso la necesidad de renunciar a los viejos métodos disciplinarios e innovar, lo que fue un proceso lento y complejo, según las formaciones sociales. Por una parte, se intentaron sistematizar las experiencias del control patronal sobre la vida de los obreros fuera de la fábrica. Esta extensión del control, y correlativamente de la disciplina impuesta, se puso en evidencia con la construcción de las ciudades o villas obreras, en la organización de la enseñanza patronal, en fin, en un conjunto de instituciones que generalmente se atribuyen a una ideología paternalista, a una voluntad de disciplinar la fábrica disciplinando su exterior. Una doble estrategia de modelamiento, en las fábricas y en las casas y mediante una estrategia de moralización social (Sierra Álvarez, 1990: 20).

Por otra parte, no se trataba solo de comprender por qué el patrón buscaba imponer su disciplina, o la forma de disciplina que en un momento dado parecía ser la mejor, sino también por qué y bajo que condiciones la disciplina era aceptada por los trabajadores. Se podría responder diciendo que la disciplina es aceptada por los trabajadores porque no pueden sino someterse a ella, al encontrarse presos de la coacción directa, o también se puede decir que sin ella la producción seria imposible. En este punto se entremezclan dos argumentos: por un 
parte los obreros no podrían hacer otra cosa, y por la otra aceptan una disciplina que consideran necesaria, indispensable para realizar sus trabajos.

Al encadenamiento disciplinario, constituido por el control normativo legal y el sometimiento a las reglas del patronazgo, se agregan otras formas que contribuyen y profundizan el proceso de subordinación (Bialowkosky, 1994: 14). Por tal motivo, resulta interesante poder verificar las formas en que la patronal intentaba guiar la legitimidad de su dominación económica y social, y como esas formas se modificaban bajo las respuestas de los obreros, de aceptación o rechazo. Esa dominación es la que permitirá mantener, en cierto sentido, un determinado orden dentro y fuera de la fábrica que garantizando el buen funcionamiento productivo.

Un problema al que debieron enfrentarse los patrones fue el de la adaptación productiva del trabajador. Distribución irregular e "irracional" del tiempo de trabajo eran la clase de problemas que los amenazaban. Esas técnicas son las disciplinas industriales que buscarán atraer, fijar y disciplinar, mediante la operación de un modelado poblacional y social (Sierra Álvarez, 1990: 10). Coincidimos con Max Weber cuando asegura que por dominación debe entenderse la probabilidad de encontrar obediencia a un mandato específico (Weber, 1994: 170). En el caso de estas cementeras, esa dominación se trasluce en la habilidad demostrada en el mantenimiento de las relaciones sociales, dentro y fuera la fábrica. El control social es un elemento insustituible en el proceso de producción, las disciplinas empleadas en el proceso de trabajo son parte necesaria para constituir la relación de subordinación en el modo de producción capitalista. Por eso, el disciplinamiento es considerado como una cuestión capital, por quienes tienen el rol y el objetivo principal de mantener constantes los aumentos de productividad (Rosendo, 1999: 242). La mayoría de los obreros que ingresaban a estas empresas eran presentados por parientes o amigos, lo que facilitaba su integración y creaba al mismo tiempo obligaciones, garantizando un compromiso de todo el grupo familiar por la conducta de cada uno de sus miembros, facilitando el mantenimiento de la disciplina dentro de la fábrica. Tal como afirma Anthony Giddens, el conflicto es un hecho irremediable de la condición humana, la fuente ineludible de lo que es creador, así como destructivo en la sociedad humana. Afirmar esto, evidentemente, no equivale a decir que el carácter y las causas de los conflictos actuales no puedan haber cambiado significativamente con respecto a los que impulsaban a los hombres en épocas pasadas (Giddens, 1996: 334). Más allá del cambio de significado, el conflicto resulta fundamental en la vida social.

Las redes de dominación, desde el punto de vista weberiano, requieren para su construcción de un mínimo de cooperación y subjetividad. Se plantea entonces, desde el punto de vista patronal, la necesidad de una forma de disciplina susceptible de ser interiorizada por los mismos trabajadores. La acción de otorgar beneficios a los trabajadores y crear lazos

$$
\text { Question, Vol. 1, N. } 62 \text {, abril-junio 2019. ISSN 1669-6581 }
$$


solidarios, garantizaba o al menos disminuía la posibilidad de malestar y reclamos de los obreros.

Max Weber, en su trabajo Tipos de dominación, nos habla de las formas de legitimidad de tal dominación por vías sutiles, donde el consenso sustituye a la imposición forzada y la resistencia se expresa bajo otras formas, también mitificadas y personalizadas y dice:

\begin{abstract}
Debe entenderse por "dominación", la probabilidad de encontrar obediencia dentro de un grupo determinado para mandatos específicos (o para toda clase de mandatos). No es, por tanto, toda especie de probabilidad de ejercer "poder" o "influjo" sobre otros hombres. En el caso concreto, esta dominación ("autoridad") en el sentido indicado, puede descansar en los más diversos motivos de sumisión: desde la habituación inconsciente hasta lo que son consideraciones puramente relaciones con arreglo a fines. Un determinado mínimo de voluntad de obediencia, o sea de interés (externo o interno) en obedecer, es esencial en toda relación de autoridad... (1944: 170).
\end{abstract}

Si bien en las relaciones personalizadas, que se observan en estas empresas cementeras, existe una clara dominación por parte del patrón hacia sus obreros, está también presenta la "voluntad de obediencia" de la que nos habla Weber. "No toda dominación se sirve del medio económico. $Y$ todavía menos tiene toda dominación fines económicos". Lo que Weber nos dice es que los motivos puramente materiales con arreglo a fines como vínculo entre las partes, implican una relación frágil y por eso es que se le añaden otros motivos o relaciones con arreglo a valores. Pero la costumbre y la situación de intereses, no menos que los motivos puramente afectivos y de valor, no pueden representar los fundamentos en que la dominación confía. Normalmente se le añade otro factor: la creencia en la legitimidad (Weber, 1944: 171).

Es decir, la autoridad debe ser legítima para poder convertirse en un elemento de dominación. Lo que resulta interesante, es poder identificar cuales son los motivos que llevan a los actores a incorporar la idea de obediencia y posterior sometimiento, el sentido que los sujetos le otorgaban a esa autoridad, que sobrepasa la simple noción de "respeto" a su jefe a lo largo del ejercicio de la autoridad. Existen, según Weber, diferentes clases de dominación, según sus pretensiones típicas de legitimidad. También afirma que existen tres tipos puros de dominación legítima y que el fundamento primario de su legitimidad puede ser de carácter racional, tradicional o carismático. Si bien no podemos llegar a encasillar a la relación patronal de la industria del cemento en uno de estos tres tipos de dominación, sabemos que allí se dio una relación particular de dominación, con características y estilo propio. En otras palabras, en el mecanismo de dominación presente en este caso la disciplina nos es un elemento puramente coercitivo, sino que se observa un proceso de interiorización de los valores productivos por parte de los 
trabajadores que legitiman esas prácticas patronales.

\section{La construcción de la villa obrera como estrategia empresarial}

Como hemos señalado, la necesidad de tener la mano de obra próxima a la fábrica hizo que la compañía emprenda la construcción de una villa obrera. Vivir cerca de la villa significaba, no solo acceder a casas de mejor calidad que el resto del pueblo, sino también a servicios que los demás no poseían: calles asfaltadas, luz eléctrica y agua corriente, en aquel momento, un bien escaso y deseable (García, 2004: 33). Al relacionar estas prácticas con la estructura social, se puede observar el proceso de reproducción social en el momento de producción de la acción cotidiana. A partir de la instalación de la fábrica y la villa obrera, se observa como la esfera de la producción -relación capital/trabajo, que implica las formas de pago, la modalidad de contratación y la modalidad de trabajo en general- y la esfera de la reproducción de los trabajadores -vivienda, educación, ocio, salud- se hallan unificadas bajo el dominio de la empresa (Neiburg, 1998: 60).

La concentración de la mayor parte de los trabajadores en los pueblos que nacieron alrededor de la empresa, hacía que también estuviera en manos de esta la organización del tiempo libre (Barbero, 1999: 179). La dimensión de los terrenos estaba calculada como para que en ellas pudiera cultivarse productos de huerta y plantarse árboles frutales. Ello ayudaría a crear ciertos hábitos propios de las sociedades campesinas y serviría al mismo tiempo para proveer a las familias de algunos alimentos para el autoconsumo. Además, desde la empresa, se fueron organizando diversas actividades recreativas como fútbol, natación, tenis y golf.

La fábrica adoptaba una forma de trabajo donde los obreros debían adecuarse al ritmo de la máquina. Se trabajaba por turnos, entrando cuando sonaba la sirena de la fábrica y saliendo cuando ésta volvía a sonar. La sirena establecía los tiempos de la familia, los horarios de comida, de reposo, de diversión etcétera.

Fue la fábrica la que pudo tener un lugar preponderante con una complejidad que se apartaba de la tradicional forma de explotación de la piedra. Con estas innovaciones los trabajadores están insertos en un nuevo contexto que cambia rotundamente su concepción del trabajo, modificando las relaciones sociales de producción. Por otra parte, se fue acentuando la relación entre lugar de trabajo y vivienda en un nuevo estilo de reproducción de la mano de obra.

La villa obrera surge entonces como estrategia de la industria. Resulta evidente la conveniencia de tener a disposición y en las mejores condiciones posibles a la mano de obra, siendo el 
aprovechamiento de la fuerza laboral uno de los componentes en el rendimiento y también para la comodidad del propio trabajador, que se veía beneficiando con los componentes sociales que eran insertados por las empresas en las villas obreras.

La asociación entre la fábrica y la villa obrera forma parte de un modelo de industrialización frecuente, no sólo en la primera etapa de desarrollo industrial, sino también utilizado preferentemente en las industrias ligadas a los recursos naturales como, por ejemplo, las agroindustrias. Al localizarse la fábrica en áreas despobladas o con muy poca población, la ausencia de un mercado de trabajo previo obligó a la industria a crear y organizar ese mercado, fijando a su personal a través de la construcción de viviendas. Para la elaboración del producto era necesario contar con una población trabajadora próxima, que estuviera ahí en los momentos que la empresa los necesitara.

\section{Las características del proceso de trabajo, producto y disciplina productiva}

Cuando nos referimos a las características del proceso de trabajo, más allá de los aspectos meramente económicos y técnicos relacionados a la producción, el objetivo es mostrar el nexo existente entre esas características y las condiciones de vida de los trabajadores que en esos procesos intervienen, al tomar en consideración todo el entorno en el cuál se reproduce un elevado porcentaje de la fuerza de trabajo.

El proceso de trabajo de la industria en general, ha ido variando notablemente a lo largo del tiempo. Lo definimos como el acto específico donde la actividad humana efectúa, con la ayuda de los medios de trabajo, una modificación deliberada de los objetos de trabajo, de acuerdo con una finalidad, para generar bienes de uso que tienen un valor social. La relación entre la fuerza de trabajo y los objetos de trabajo, actúa mediante los diversos medios de trabajo que han ido emergiendo históricamente, y han sufrido profundas transformaciones (Neffa, 1998: 15).

La complejidad del trabajo humano se visualiza a través de sus diversas dimensiones materializándose a través de las relaciones que establece el trabajador en si mismo y con los demás trabajadores y con la sociedad en general, asumiendo una particularidad propia de la organización de trabajo. De aquí que considerar el trabajo implica concebirlo como un proceso entre el hombre y la naturaleza, a partir del cuál se generan bienes y servicios, pudiendo contribuir al desarrollo de la personalidad del trabajador, según las condiciones del trabajo, y constituyendo un hecho social, ya que el trabajador en todas sus relaciones forma parte de una realidad colectiva actuando con otros seres humanos que cooperan de manera simple o compleja (Galafassi, 2002: 1).

Question, Vol. 1, N. o 62, abril-junio 2019. ISSN 1669-6581 
Es sabido que la racionalización de la producción industrial se fue modificando a lo largo del tiempo. La aplicación de los principios taylorista y fordista en la producción, posibilitó la posterior emergencia y articulación de las innovaciones que permitieron las modificaciones en el proceso de trabajo y en la organización de las empresas. Con Taylor se produce la entrada del reloj en el taller, y con la medida de los tiempos y los movimientos fue posible la sustitución progresiva del obrero profesional de oficio por obreros carentes de calificación y organización. La ley del cronómetro barre así el principal obstáculo que a comienzos del siglo XX encuentra la acumulación del capital. Por otro lado, la cadena de montaje de Ford es el paso siguiente, el gesto obrero reducido a movimientos elementales se ve sometido a la normalización de las piezas abriendo la producción a grandes series. De esta forma, las condiciones salariales y de consumo se van transformando por la generalización de la producción masiva (Neffa, 1998: 87). Taylor, Ford y detrás de ellos, el ejército de los cronometradores y analizadores han conseguido desde la década de 1920 una nueva economía que regula los aparatos de producción, y con ella, la sociedad civil en su conjunto parece presa de un ritmo nuevo y singular (Neffa, 1998: 88). Tanto el taylorismo como el fordismo buscaron lograr una economía de tiempo de trabajo con medios diferentes. Primero, el taylorismo, mediante la asignación de tiempos predeterminados y estandarizados en virtud de los estudios de tiempos y movimientos y la división social y técnica del trabajo, relacionando el rendimiento con la remuneración. Segundo, el fordismo lo hizo imponiendo los tiempos y la decadencia de los operarios, actuando de manera exterior, "objetiva" y mecánica, por medio de la cadena de montaje cuya cadencia es regulada según los objetivos de los responsables de la producción (Neffa, 1998: 18).

Una de las principales ideas de Taylor es que la fuente de riqueza no la constituye el dinero, sino el trabajo. Asegura que la riqueza proviene del suelo y de lo que se encuentra en el suelo, y después, del trabajo del hombre. En efecto, solo un aumento de la productividad del trabajo puede favorecer el desarrollo de la acumulación de capital (Sapeli, 1993: 34). De allí, debemos partir para comprender la dinámica productiva de las diversas empresas.

Se trataría sobre todo de distanciar al obrero del proceso de trabajo, del poder y la libertad que este tendría para decidir e influir en el mismo, y en su lugar establecer normas patronales que dirijan completamente el proceso de trabajo. Además, debemos tener cuenta que, dentro de las fábricas, los trabajadores no necesitaban manejar conocimientos específicos, sino que fundamentalmente contaban con su disposición al trabajo y su servicio a la empresa. De esta manera, las formas productivas adoptadas por el taylorismo y el fordismo se diferencian notablemente de las experiencias originarias. Las dificultades que tuvieron para adaptarse de manera rígida, copiando simplemente el modelo original, dieron lugar a numerosas 
adaptaciones para hacerlos operacionales (Neffa, 1998: 12). De esta forma, fue posible la entrada masiva de trabajadores no especializados en la producción, quedando expulsado de la fábrica no solo el obrero de oficio, sino también el obrero organizado, que resultaba peligroso para la concepción de disciplina que se buscaba implementar.

La redefinición de las estrategias empresariales vinculadas a la gestión de los recursos humanos se vincula entre otras cosas, a la organización del trabajo y el interés se centra en interpretar a través de distintos puntos de vista los cambios más significativos de dichas estrategias aplicadas al proceso de producción. Las diversas formas de producción y de la organización del trabajo en forma masificada han permitido ver la existencia de situaciones heterogéneas, que no lograban ser vistas con claridad tiempo atrás. La diferenciación y visualización de procesos particulares, constituye entonces una manera muy rica de encarar el estudio de casos, enfatizando el análisis de procesos locales, que, si bien están inscriptos en la evolución general del trabajo y la producción, pueden asumir características específicas por la incidencia de circunstancias propias, como las estrategias de los actores a través de su conformación histórica, la especificidad de la producción y las características del medio natural (Galafassi, 2002: 3).

La predominancia de establecimientos fabriles en la zona serrana próxima a Olavarría, desde el origen de la explotación minera, imprime rasgos muy singulares a la organización del trabajo que, junto con las particularidades del medio natural y la especificidad de la producción, componen una compleja trama de situaciones que marcan un sistema de funcionamiento singular.

\section{Tiempo, disciplina y producción}

Uno de los problemas que debió enfrentar la industrialización fue la gran supervivencia de modos de vida tradicionales, incorporados en los trabajadores, expresado en una gran dificultad al momento de disciplinar la mano de obra que debía adaptarse a los nuevos ritmos de la producción industrial. El tiempo de trabajo era irregular, y la cultura de los trabajadores debía adaptarse a los cambios demandados por las exigencias laborales (Thompson, 1984: 257). La sanción expresaba la corrección de un aspecto tradicional de comportamiento, que no era funcional al modelo de obrero industrial que se necesitaba en determinados contextos, por ello la necesidad de corregir y cambiar este aspecto.

Edward Thompson nos habla de una diferencia visible en la adaptación de la cultura regional de los trabajadores. Es decir, que no existió una generalidad de respuestas a las exigencias de 
una industria que demandaba pautas de comportamientos y modos de vida. Dentro de esa adaptación regional, las particularidades de cada caso exigen a la empresa adecuar las estrategias empresariales necesarias para poder realizar la producción bajo normas disciplinarias. Así, las respuestas y expresiones fueron diferentes en cada etapa de la industria, en cada región y, a medida que la industria se desarrollaba, evolucionaba en cuanto a la tecnología incorporada, pero también modificaba sus pautas en cuanto a las relaciones sociales construidas.

Las relaciones laborales aquí analizadas, estaban fundamentalmente basadas en relaciones sociales de disciplinamiento visibles en las plantas cementeras de principios del siglo XX que incorporaron la disciplina, los horarios y las normas de seguridad, además de reproducir el orden de la fábrica en el hogar y la reproducción social de los trabajadores.

En el proceso de trabajo, el ritmo de producción y en consecuencia el volumen producido, están regulados por el ritmo de trabajo humano: el número de sus intervenciones por unidad de tiempo y su intensidad. Dada la productividad del trabajo, definida como el cociente entre el volumen de la producción y el número de horas de trabajo, y si no se modifica la dotación anterior de trabajos, si se quiere aumentar la producción, se debe contratar más trabajadores, prolongar la duración de la jornada, o simplemente intensificar el trabajo para hacer una "economía de tiempo". El patrón debía utilizar el tiempo de su mano de obra y ver que no se malgaste.

El componente correctivo de la disciplina, y su expresión por medio de la sanción, lograron modificar pautas tradicionales de comportamiento que debían ser disciplinadas, por ejemplo, el cumplimiento de horarios y reglamentos establecidos por la fábrica. Siguiendo al autor Thompson, vemos como aparece en la fábrica una nueva disciplina del tiempo y fue precisamente en las industrias donde esa disciplina se imponía más rigurosamente, donde la contienda sobre las horas se hizo más intensa.

En charlas informales con algunos trabajadores, recuerdan que dentro de las fábricas de cemento había mucha disciplina:

\footnotetext{
En el trabajo había mucha disciplina. Por falta o llegada tarde se descontaba el día. A fin de año había premios por presentismo y puntualidad, y también, por eficiencia en el trabajo o para quienes inventaran algún procedimiento que mejorar la producción. Hubo muchos de estos premios, a capataces, obreros o ingenieros.
}

Generalmente se relacionaba la fuerte disciplina con la nacionalidad de quienes estaban a cargo del funcionamiento de la empresa. "Eran alemanes, por eso eran tipos duros, se vestían con 
sacos largos, corbatas, y donde encontraban algo fuera de lugar, se enojaban mucho" (Alonso de Rocha, 1995: 302).

La mención al personal jerárquico, caracterizado por una particular vestimenta, estaría indicando pautas de distinción dentro del grupo de empleados de la empresa y, por otra parte, era un símbolo de autoridad y de respeto. La nacionalidad del personal que rodeaba al dueño de la empresa, genero la imagen de hombres fuertemente disciplinados y encargados de llevar a la práctica su concepción de orden dentro de la fábrica.

Los testimonios expresan a su vez la posibilidad que los trabajadores tenían para poder intervenir en el proceso de producción. La empresa incentivaba y premiaba a los trabajadores que lograban realizar algún tipo de mejora en la producción. De esta forma, el conocimiento obrero, que en la mayoría de los casos partía de la observación y la experiencia, era reconocido, destacado y premiado por la empresa. Ese logro que modificaba la producción industrial, aquel reconocimiento hacia el trabajador por su capacidad de mejorar la producción, beneficiaba notablemente a la empresa que de esta forma se aseguraba la posibilidad de incluir el conocimiento de los trabajadores en el control total del proceso de producción de cal y cemento.

Tal como asegura Neffa, en el proceso de trabajo, el ritmo de producción y el volumen producido están regulados por el ritmo de trabajo humano: el número de sus intervenciones por unidad de tiempo y su intensidad. La apropiación del saber obrero, y su aplicación directa en el proceso de trabajo, hace que si se busca aumentar la producción se deben contratar más trabajadores, o prolongar la duración de su jornada, o en todo caso, la búsqueda apunta a intensificar el trabajo para hacer una "economía de tiempo" apropiándose a su vez del "saber hacer" de los trabajadores (Neffa, 1998: 23).

Dentro de estas empresas, estaba presente la idea de sanción e incentivo para quienes intervenían directamente en la producción, es decir, los trabajadores. En términos de tiempo de trabajo y calidad del producto, vemos que el incentivo ejercido hacia los trabajadores por medio de premios y reconocimientos, aseguraba la posibilidad de encontrar mejoras en la calidad del producto y, por otra parte, la sanción evitaba la pérdida de tiempo que el obrero dedicada a la producción. Detrás de la aplicación de sanciones y premios se gestaba un modelo de organización empresarial, donde la disciplina constituía una variable fundamental para su normal funcionamiento.

Aparece como rasgo compartido la noción de sanción e incentivo, como variables aplicadas a la producción que incidía directamente en el tiempo de trabajo y la calidad de la producción elaborada. La limitación de la autonomía no buscaba solo aumentar la productividad, reducir los costos de la mano de obra por unidad de producto, y reducir el nivel de las calificaciones profesionales requeridas, sino también desalentar toda posibilidad de control de los obreros 
sobre su proceso de trabajo que pudiera perturbar la regularidad.

En el proceso de control del tiempo de trabajo, no solo importaba la disciplina dentro de la fábrica, sino que además había que disciplinar su exterior, es decir, el barrio obrero que la rodeaba. La unión entre ambos espacios -fábrica y villa obrera- para su posterior disciplinamiento, se buscó por medio de la construcción de relaciones laborales personalizadas y de poder, entre los trabajadores y su patrón.

\section{El paternalismo como forma de gestión empresarial}

Como es sabido, una de las funciones más importantes de la familia es la de socialización, definida por el proceso por el que la herencia, y en particular las normas de una sociedad o reglas de comportamiento, se trasmiten de una generación a otra (Burke, 1993). Cuando nos referimos a la creación de la fábrica y su villa, es necesario mencionar la posterior construcción de un fuerte lazo de unión y de pertenencia a la empresa que estaba representada por el eslogan de "la familia".

Así, partiendo de la identificación entre la familia y la empresa, se construirá el discurso paternalista y aparecerá la idea de la conveniencia de organizar actividades culturales y deportivas por el efecto moralizante. Se aconsejará la intervención de la empresa en los momentos claves de la vida de los trabajadores, de la biografía obrera, como bodas, nacimiento de los hijos, fallecimiento, etcétera. De esta forma, los valores que forman parte de la unidad familiar van a ser los pilares que sostengan el pensamiento paternalista.

A los patrones e ideólogos paternalistas, no se les escapaba que el sentimiento de familia existía realmente en los medios populares. No se les escapaba tampoco, que ese sentimiento presentaba una fuerza inusitada, heredada de las formas familiares del Antiguo Régimen (Sierra Alvarez, 1998: 119). En el pensamiento político del patrón, un obrero, que dentro de su ámbito privado incorpore determinadas pautas morales encargadas de garantizar la tranquilidad y estabilidad del hogar, de una u otra forma trasladaría su bienestar dentro de la fábrica.

Toda formación social reproduce la fuerza de trabajo mediante el salario, la calificación de esa fuerza mediante la educación, y por último, reproduce constantemente la capacidad del trabajador al orden social, a través de una política-ideológica que pauta su vida entera en el trabajo, la familia, las diversiones, de modo que todas sus conductas y relaciones tengan un sentido compatible con la organización social dominante (Geertz, 1978: 20). Mediante la reproducción de la adaptación, la clase dominante busca construir y renovar el consenso de las masas a la política que favorece sus privilegios económicos. Una política hegemónica integral 
requiere la propiedad de los medios de producción, pero también el control de los mecanismos necesarios para la reproducción material y simbólica de la fuerza de trabajo y de las relaciones de producción, es decir, otras instituciones capaces de calificar a los trabajadores y suscitar su consenso (García Canclini, 1990: 50).

Creemos que, en ningún contexto, la hegemonía de una clase puede sostenerse únicamente mediante el poder económico. En un extremo, encontramos los mecanismos que, mediante la vigilancia o el castigo, como asegura Focault, garantizaban el sometimiento (2002: 142). Pero, no hay clase hegemónica que pueda asegurarse durante largo tiempo su poder económico solo con el poder represivo. Entre ambos, cumple un papel clave el poder cultural y, de esta forma, se fueron imponiendo normas culturales-ideológicas que adaptaron a los miembros de una comunidad a una estructura económica.

Esa eficacia se apoya en la necesidad de todo individuo de ser socializado, adaptarse a algún tipo de estructura social que le permita desarrollarse personalmente y hallar seguridad afectiva. De los hábitos surgen prácticas, en la medida en que los sujetos que las internalizaron se hallaron situados dentro de la estructura de las clases en posiciones propicias para que dichos hábitos se actualicen. De esta forma, la empresa consiguió mantener y acrecentar su producción sin implicarse en conflictos laborales.

La gestión de la fuerza de trabajo, puede llevarse a cabo de muchas maneras: autoritaria, despótica, paternalista, discrecional, democrática, participativas, etcétera. El estilo adoptado influirá sobre la vida afectiva y relacional de los trabajadores subordinados e incluso puede facilitar o dificultar la comprensión del trabajo prescripto (Neffa, 1988: 87). Los recursos paternalistas como la entrega de viviendas, el reclutamiento de un mismo grupo familiar o la enseñanza del oficio, tendían a integrar a todo el personal obrero y a lograr que el mismo se identifique con la empresa, como si esta fuese una gran familia, eslogan que encontramos como referente en otras industrias donde también se desarrollan prácticas paternalistas. La empresa realizaba un llamado a transitar el camino del orden, de la disciplina, y junto a la idea de autodisciplina, al autocontrol de la tarea propia, se propiciaba la vigilancia sobre la tarea que realizaban los compañeros.

Sobre las prácticas paternalistas donde el padre/patrón da, otorga, se fue construyendo una red de relaciones de reciprocidad donde el que recibe una atención, se siente en la obligación de devolverla, aunque sea de otra forma. Así, la beneficencia se convirtió en una interacción en un intercambio reciproco que supone dar, recibir y devolver. Todas estas estrategias no son más que algunos de los mecanismos utilizados para la gestación de consenso, de cierto grado de aceptación, para cada patrón particular en el manejo de su fábrica. Estas estrategias, lo constituyen la entrega de viviendas a los trabajadores y sus familias, el tipo de reclutamiento

Question, Vol. 1, N.0 62, abril-junio 2019. ISSN 1669-6581

Instituto de Investigaciones en Comunicación | Facultad de Periodismo y Comunicación Social | Universidad Nacional de La Plata La 
desplegado por la empresa, la enseñanza del oficio y los diversos premios entregados como incentivo de trabajo (Neffa, 1998: 166).

Estaba presente la idea que, si el trabajador se encontraba trabajando en un ambiente confortable, a su agrado, su nivel de rendimiento sería superior. Ya para el año 1938, el establecimiento industrial de Calera Avellaneda se presentaba como:

\begin{abstract}
Paisaje de fuerte belleza y tonos característicos, semeja las regiones serranas de los pueblos que pintan las leyes admirables. $Y$ en medio de aquella aguafuerte de rasgos tan personales y de matices tan variados, el establecimiento "San Jacinto", como una demostración evidente de la evolución que ha ido clasificando al mismo, como uno de los modelos más fervientes de esfuerzo y la inteligencia del hombre y que ha transformado la quietud lugareña, en su foco de actividad y laboriosidad, poniéndose a todo con las maquinarias que elaboran la grandeza industrial del país. Año tras año, la preocupación del Directorio de la sociedad, ha contribuido a realizar una obra, que hoy es admirada como un modelo por su organización, su capacidad, su disciplina (El Popular, 1935: 107).
\end{abstract}

Voluntariamente o no, se ve expresada aquí la idea de modelo, de un esquema propuesto y seguido con el objetivo de alcanzar un determinado fin, con un estilo propio, diseñado por la dirigencia empresarial de aquel momento y adaptándolo a las demandas de la época. A continuación, se agrega: "Queda plasmada la convicción de que si el trabajador siente un bienestar, tanto dentro como fuera de la fábrica, su satisfacción se traduciría en una óptima respuesta ofrecida a la empresa".

\title{
Consideraciones finales
}

La instalación de la industria extractiva en la zona serrana motivó la iniciación del desarrollo económico-productivo local, que atrajo mano de obra de origen inmigrante constituyendo así un mercado de trabajo hasta entonces inexistente. Las cementeras debían instalarse cerca de las canteras, de donde extraían su materia prima, y por el tipo de proceso de trabajo vigente demandaban gran cantidad de obreros que, en función de un ciclo de producción continuo, debía residir cerca de la fábrica. El nacimiento de las villas obreras obedeció a la necesidad de contar con un mercado de trabajo próximo y estable. Tanto en la fábrica como en la villa se producía la adaptación productiva de los trabajadores, proceso en el cual intervenía no sólo el salario sino también el acceso al usufructo de una vivienda para la familia obrera. Es decir que 
la empresa establecía relaciones con sus trabajadores en las esferas de la producción y la reproducción de la fuerza de trabajo, estrechamente ligadas entre sí.

A medida que el aparato de producción se fue haciendo más importante y más complejo, a medida que aumentaba el número de obreros y la división del trabajo, las tareas de control se hicieron más necesarias y difíciles. Vigilar pasó a ser entonces una función definida, como ha señalado Michel Foucault, pero que debió formar parte integrante del proceso de producción y acompañarlo en toda su duración. En este caso, el control se expresaba por medio de diversos mecanismos, aplicados con la intención de mantener a los trabajadores en sus puestos de trabajo, en una fábrica lejana de la ciudad y en un contexto de gran demanda de mano de obra. Por lo tanto, la disciplina fue ejercida por la empresa dentro y fuera de la fábrica, por medio de mecanismos formales e informales que se construyeron y perfeccionaron desde sus orígenes. Adentro de la planta, el control sobre el ritmo de producción era constante; afuera, en la villa obrera, ese control continuaba por medio de los vínculos personales y las políticas sociales diseñadas por el patrón.

Gracias a la técnica de vigilancia, el poder y el dominio se articulaban en un determinado espacio efectuándose por medio de mecanismos o prácticas sin recurrir al exceso, a la fuerza o a la violencia. Los patrones sabían que la entrega de beneficios a "su gente" era la clave que garantizaba su fidelidad y que ésta facilitaría la aplicación de los principios disciplinarios. Dentro de ese modelo, que abarcaba la fábrica y la villa obrera, se generaron pautas de conducta y se difundieron valores morales que, al ser incorporados por los mismos actores, sirvieron para integrarlos al modelo empresarial de relaciones sociales: la "gran familia".

Para ello, la política paternalista desplegaba una diversidad de recursos, como la entrega de viviendas, el reclutamiento de trabajadores de un mismo grupo familiar o nacional, la enseñanza del oficio y una amplia variedad de actividades que sostenían la sociabilidad de los habitantes de la villa obrera. Esta puede ser interpretada como un "espacio pedagógico", es decir, territorio y un espacio social de intervención y de puesta en práctica de técnicas y procedimientos disciplinarios, y de "obras sociales".

Si bien el discurso patronal difundió la idea de igualdad social, existió una contraposición entre los principios jerárquicos y los igualitarios cuando las estrategias empresariales se pusieron en práctica, ya que requirieron necesariamente de la jerarquía para alcanzar el disciplinamiento transformado en orden.

La transmisión de hábitos y valores se realizó a través de diferentes actividades sociales, desplegadas con la idea de fomentar la solidaridad y el compañerismo, objetivos funcionales a la armonía entre capital y trabajo. Estas actividades y espacios sociales alentaron la interacción constante de los habitantes de la villa obrera, y constituyeron ámbitos de sociabilidad donde 
surgieron imágenes e ideas precisas. Así, se conformaron en el plano simbólico las vías para la incorporación de los trabajadores al modelo fabril paternalista. Estos aceptaron esas relaciones sociales, conscientes que la empresa trascendía su influencia más allá de la simple relación laboral, y ello casi obligaba a una retribución a su patrón.

Las estrategias desplegadas por los empresarios del cemento durante un contexto particular, que acompañaron al desarrollo económico de la ciudad de Olavarría, fueron configurando y expresando las diferentes relaciones de poder, al mismo tiempo que contribuyeron a la formación de una identidad particular para la ciudad. Más allá de la construcción de poder en sus propias empresas, fueron configurando relaciones de poder con el municipio de Olavarría, que les generó un beneficio concreto a cada una de las partes. Los empresarios pudieron aumentar sus producciones de cemento y el municipio construir la identidad que actualmente permite que se defina a Olavarría como la ciudad del cemento.

\section{Bibliografía}

Alonso de Rocha, A. (1995). Gente del cemento. En Temas de Historia Oral, Primer encuentro nacional de historia oral, Municipalidad de la ciudad de Buenos Aires.

Babiano Mora, J. (1998). Paternalismo industrial y disciplina fabril en España (1938-1958). España: Concejo Económico y Social.

Barbero, M. I. y Ceva, M. (1997). El catolicismo social como estrategia empresarial. El caso de Algodonera Flandria (1924-1955). Anuario IHES, 12, Instituto de Estudios Históricos Sociales, Facultad de Ciencias Humanas, Universidad Nacional del Centro, Tandil.

Bialakowsky, A. y Fernández, B. (1994). Las articulaciones laborales. Los estibadores del puerto de Buenos Aires. Los fundamentos de la ciencia del hombre. Argentina: Centro Editor de América Latina.

Burke, P. (1998). Historia de los acontecimientos y renacimiento de la narración. En Formas de hacer la historia. Madrid: Alianza.

El Popular (1935). Anuario del Diario El Popular. Olavarría, Argentina: Autor.

Foucault, M. (2002). Vigilar y castigar. Nacimiento de la prisión. Argentina: Siglo XXI editores.

Galafassi, G. (2002). Reestructuración productiva, organización del proceso de trabajo y manejo de tecnologías: Un estudio de caso en la producción frutícola y forestal. Mundo Agrario, 2(4), La Plata, junio/julio.

García, M. (2004). La villa von Bernard. Entre violetas, aromos y recuerdos. Olavarría: Autor.

García Canclini, N. (1990). Introducción: La sociología de la cultura de Pierre Bordieu. En 
Bourdieu, P. Sociología y Cultura. México: Grijalbo.

Gaudemar, J. P. (1981). Preliminares para una genealogía de las formas de disciplina en el proceso capitalista de trabajo. En Espacios de poder. Madrid: Ediciones de la Piqueta.

Geertz, C. (1978). La interpretación de las culturas. México: Gedisa.

Giddens, A. (1996). La estructura de clases en las sociedades avanzadas. Madrid: Alianza editorial.

Leite López, J. S. (1994). Transformaciones políticas de una militancia religiosa. Antropología Social. Comunicacoes do PPGAS, 4, Museu Nacional-UFRJ, Río de Janeiro, pp. 114138.

Neffa, J. (1998). Los paradigmas productivos Taylorista y Fordista y su crisis: una contribución a su estudio desde la teoría de la Regulación. Argentina: Lumen-Hvumenitas.

Neiburg, F. (1998). Fábrica y Villa Obrera: Historia social y antropológica de los obreros del cemento. Buenos Aires: Centro Editor de América Latina.

Rosendo, R. (1999). Disciplina y control social del trabajo en tiempos de la producción postfordista. En Neufeld, M. R. Antropología social y política. Hegemonía y poder: el mundo en movimiento. Eudeba. Universidad de Buenos Aires.

Sapeli, G. (1993). La empresa como sujeto histórico. En Barbero, M. I. Historia de empresas. Aproximaciones historiográficas y problemas en debate (Estudio preliminar y presentación). Buenos Aires: Centro Editor de América Latina.

Sierra Álvarez, J. (1990). El obrero soñado. Ensayo sobre el paternalismo industrial (Asturias, 1860-1917). España: Siglo veintiuno editores.

Thompson, E. (1984). Tradición, revuelta y conciencia de clase. Barcelona: Crítica.

Villafañe, A. (1999). Proceso de transformación social del espacio rural-urbano pampeano. El caso de la conformación de localidades minero-agrarias en el Partido de Olavarría, Provincia de Buenos Aires. VII Jornadas Interescuelas/Departamento de Historia, UNCPBA, FCS, Neuquén 22 al 24 de septiembre.

Weber, M. (1944). Economía y sociedad. Esbozo de sociología comprensiva. México: Fondo de Cultura Económica. 